\title{
Image-based configuration and interaction for large neural network simulations
}

\author{
Mark Hereld ${ }^{*}$, Hyong C Lee ${ }^{2}$, Wim van Drongelen ${ }^{2}$ and Rick L Stevens ${ }^{1}$
}

Address: ${ }^{1}$ Mathematics and Computer Science Division, Argonne National Laboratory, Argonne, IL USA and ${ }^{2}$ Department of Pediatrics, University of Chicago Hospitals, The University of Chicago, Chicago, IL USA

Email: Mark Hereld* - hereld@mcs.anl.gov

* Corresponding author

from Sixteenth Annual Computational Neuroscience Meeting: CNS*2007

Toronto, Canada. 7-12 July 2007

Published: 6 July 2007

BMC Neuroscience 2007, 8(Suppl 2):P22 doi: I0.I |86/I47|-2202-8-S2-P22

(C) 2007 Hereld et al; licensee BioMed Central Ltd.

\section{Background}

Large neural network simulations are becoming more complex to set up. They require modeling at multiple scales, include the effects of many interacting physical processes, encompass greater detail, and consume greater computational resources. The drive to solve problems that rely on increasingly complex codes will soon land us in the realm of petascale computing. How will we manage such simulations, configure them, and accurately aim them at the problems we're trying to solve? Simulation is an increasingly expensive process, with each run providing data to inform configuration and targeting of subse-

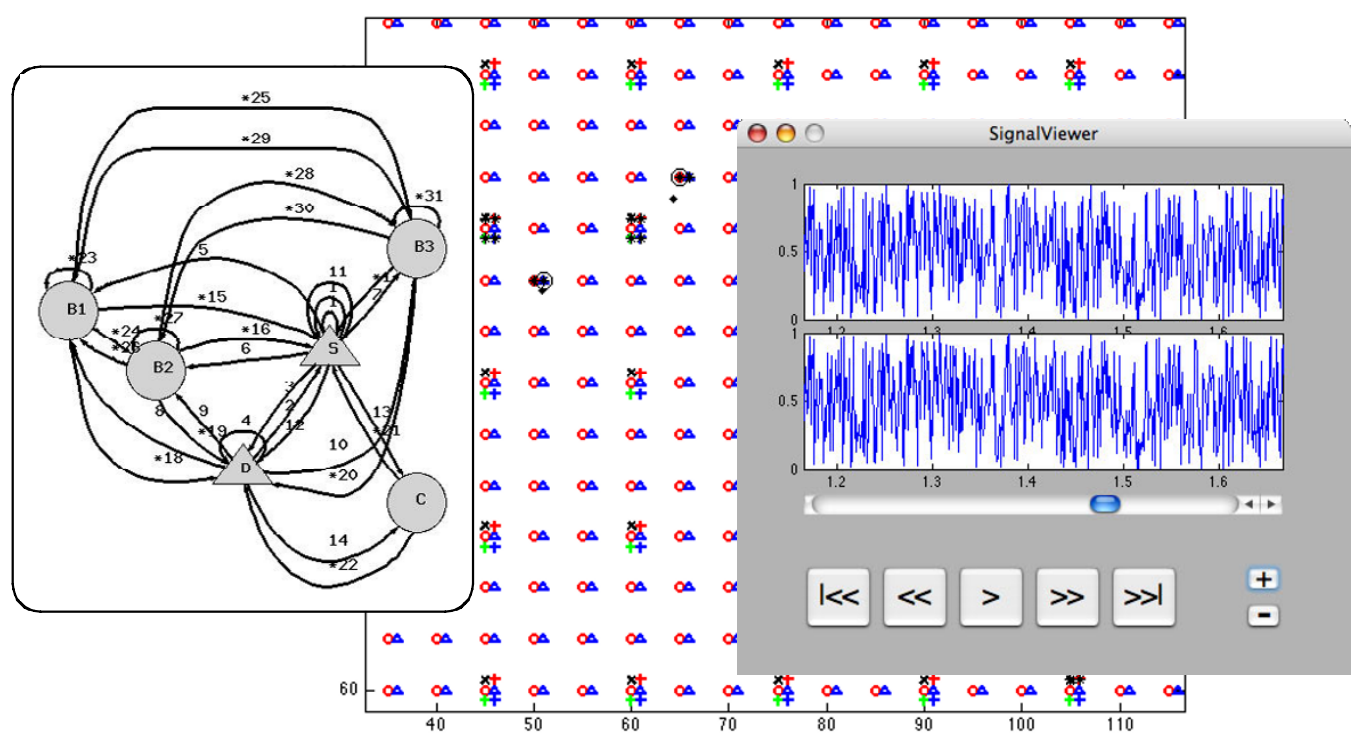

Figure I

Framework for interacting with large simulations. 
quent runs. Hence, it is vital to configure and execute simulations efficiently in order to minimize time spent on the computer cycles as well as time spent interpreting simulation results and designing follow-up experiments. We are developing a framework for interacting with and configuring large simulations using image-based interfaces generated automatically from the simulation source code.

Figure 1 shows a working prototype of some of the key components of the interactive framework. The diagram at the left is an automatically generated view of the probabilistic wiring diagram showing excitatory $\left({ }^{*}\right)$ and inhibitory connections between pyramidal, basket, and chandelier cell types. The central image is an automatically generated physical layout of a portion of the neurons in a larger patch of the neocortex simulation. Circles, triangles, pluses, and exes correspond to superficial and deep pyramidal, basket, and chandelier cells. The mouse has been used to select two cells in the subpatch, which caused the signal viewer shown on the right to launch (not wired to a live simulation in this prototype).

\section{Conclusion}

The goal of the project is to create an interface to supercomputing platforms that will enable scientists to directly engage the live simulation during its critical setup and initial phases and at later times for monitoring and redirecting. This capability will enable rapid intuition building and will improve scientists' effectiveness in deploying productive, well-targeted experiments across research domains.

\section{Acknowledgements}

This work was supported in part by the Falk Foundation, the Linn family, and the U.S. Department of Energy under Contract DE-AC02-06CHI I 357.
Publish with Biomed Central and every scientist can read your work free of charge

"BioMed Central will be the most significant development for disseminating the results of biomedical research in our lifetime. " Sir Paul Nurse, Cancer Research UK

Your research papers will be:

- available free of charge to the entire biomedical community

- peer reviewed and published immediately upon acceptance

- cited in PubMed and archived on PubMed Central

- yours - you keep the copyright

Submit your manuscript here:

http://www.biomedcentral.com/info/publishing_adv.asp 